Herz 2020 · 45:409-420

https://doi.org/10.1007/s00059-020-04935-x

Published online: 19 May 2020

(c) The Author(s) 2020

\author{
Antti Saraste ${ }^{1,2} \cdot$ Juhani Knuuti ${ }^{1}$ \\ 'Turku PET Centre, Turku University Hospital and University of Turku, Turku, Finland \\ ${ }^{2}$ Heart Center, Turku University Hospital, Turku, Finland
}

\section{ESC 2019 guidelines for the diagnosis and management of chronic coronary syndromes}

\author{
Recommendations for cardiovascular \\ imaging
}

\section{Background}

The European Society of Cardiology (ESC) recently published the 2019 ESC guidelines on the diagnosis and management of chronic coronary syndromes (CCS; [1]). Due to variable and often atypical symptoms, objective tests are often necessary to confirm the diagnosis of obstructive coronary artery disease (CAD), exclude alternative diagnoses, and assess the severity of underlying disease. In this article, we summarize the recommendations for cardiovascular imaging in the assessment of patients with suspected obstructive CAD in the 2019 ESC guidelines together with recent data underlying the recommendations.

The 2019 guidelines focus on the spectrum of CCS, excluding the situations in which an acute coronary event, often with coronary thrombus formation, dominates the clinical presentation [1]. The term "chronic coronary syndromes" emphasizes the fact that despite stable symptoms, CAD is a dynamic process of atherosclerotic plaque accumulation and functional alterations of coronary circulation that can be modified by lifestyle, pharmacological therapies, and revascularization, which may result in disease stabilization or regression [1]. The guidelines identified six clinical scenarios most frequently encountered in clinical practice. These included suspected CAD and "stable" angina symptoms and/or dyspnea; new onset of heart failure or left ventricular (LV) dysfunction and suspected CAD; stabilized symptoms <1 year after an acute coronary syndrome event or revascularization; asymptomatic and symptomatic patients $>1$ year after initial diagnosis or revascularization; angina and suspected vasospastic or microvascular disease; as well as asymptomatic subjects in whom $\mathrm{CAD}$ is detected at screening.

\section{Diagnostic approach}

The diagnostic approach in a patient with suspected obstructive CAD can be described as a series of successive steps [1]. An initial step is to assess the symptoms and signs so as to exclude patients with possible unstable angina or other forms of acute coronary syndrome. In other patients, step 2 is to evaluate the patient's general condition and quality of life. Comorbidities and other possible causes of the symptoms that potentially influence therapeutic decisions are considered. Step 3 includes basic testing and assessment of LV function. A resting transthoracic echocardiogram is recommended for all patients to exclude alternative causes of angina, identify regional wall-motion abnormalities suggestive of CAD, determine LV ejection fraction for risk-stratification purposes, as well as to evaluate diastolic function (• Fig. 1; [1]). Cardiac magnetic resonance (CMR) imaging may be considered in patients with an inconclusive echocardiogram.

In step 4 , the pre-test probability (PTP) and clinical likelihood of obstruc- tive $\mathrm{CAD}$ are estimated and, on this basis, diagnostic testing strategies, either noninvasive or invasive, are offered to selected patients in order to establish the diagnosis of CAD (step 5).

Once the diagnosis of obstructive CAD has been confirmed, the patient's event risk will be determined (step 6). Risk stratification has a major impact on therapeutic decisions, particularly identification of patients at high event risk who may benefit from revascularization beyond the amelioration of symptoms $[1,2]$. Event risk stratification is recommended based on clinical assessment and the results of the diagnostic test initially employed for making the diagnosis of CAD (- Fig. 1). An important part of the risk assessment is evaluation of $\mathrm{LV}$ ejection fraction by echocardiography. Systolic function can be reduced without a decrease in ejection fraction, and a decreased global longitudinal strain (GLS) by $>2$ standard deviations from the lower normal reference value has demonstrated incremental value in risk assessment of patients with CCS, especially in those with LV ejection fraction $>35 \%$ [3-5].

\section{PTP and clinical likelihood of CAD}

Estimation of the PTP and clinical likelihood of obstructive CAD serves to identify patients who require further investigation or treatment (• Fig. 1; [1]). The prevalence of obstructive CAD among 
Table 1 Performance of diagnostic tests for the detection of anatomically significant ( $>50 \%$ stenosis) or functionally significant (FFR $\leq 0.80) C A D^{a}$

\begin{tabular}{|c|c|c|c|c|}
\hline Test & $\begin{array}{l}\text { Sensitivity } \\
(\%, 95 \% \mathrm{Cl})\end{array}$ & $\begin{array}{l}\text { Specificity } \\
\text { (\%, 95\% Cl) }\end{array}$ & $+\mathrm{LR}$ & -LR \\
\hline \multicolumn{5}{|c|}{ Anatomically significant $C A D$} \\
\hline Exercise ECG & $58(46-69)$ & $62(54-69)$ & $1.53(1.21-1.94)$ & $0.68(0.49-0.93)$ \\
\hline Stress echo & $85(80-89)$ & $82(72-89)$ & $4.67(2.95-7.41)$ & $0.18(0.13-0.25)$ \\
\hline Coronary $\mathrm{CTA}^{\mathrm{b}}$ & $96(93-98)$ & $82(75-87)$ & $8.9(6.1-13.5)$ & $0.022(0.01-0.04)$ \\
\hline SPECT & $87(83-90)$ & $70(63-76)$ & $2.88(2.33-3.56)$ & $0.19(0.15-0.24)$ \\
\hline PET & $90(78-96)$ & $85(78-90)$ & $5.87(3.40-10.15)$ & $0.12(0.05-0.29)$ \\
\hline Stress CMR & $90(83-94)$ & $80(69-88)$ & $4.54(2.37-8.72)$ & $0.13(0.07-0.24)$ \\
\hline \multicolumn{5}{|c|}{ Functionally significant $C A D$} \\
\hline Coronary CTA & $93(89-96)$ & $53(37-68)$ & $1.97(1.28-3.03)$ & $0.13(0.06-0.25)$ \\
\hline SPECT & $73(62-82)$ & $83(71-90)$ & $4.21(2.62-6.76)$ & $0.33(0.24-0.46)$ \\
\hline PET & $89(82-93)$ & $85(81-88)$ & $6.04(4.29-8.51)$ & $0.13(0.08-0.22)$ \\
\hline Stress CMR & $89(85-92)$ & $87(83-91)$ & $7.10(5.07-9.95)$ & $0.13(0.09-0.18)$ \\
\hline \multicolumn{5}{|c|}{$\begin{array}{l}\text { CAD coronary artery disease, CTA computed tomography angiography, } C I \text { confidence interval, } \\
\text { ECG electrocardiogram, FFR fractional flow reserve, } L R \text { likelihood ratio, PET positron emission } \\
\text { tomography, SPECT single-photon emission computed tomography (exercise SPECT with or without } \\
\text { dipyridamole or adenosine), Stress CMR stress cardiac magnetic resonance, Stress echo exercise } \\
\text { stress echocardiography, }+L R \text { positive likelihood ratio, }-L R \text { negative likelihood ratio } \\
\text { aModified from [19] } \\
\text { bData from [20] }\end{array}$} \\
\hline
\end{tabular}

patients with suspected CAD has substantially decreased over time. A pooled analysis [6] of three contemporary study cohorts including patients evaluated for suspected CAD [7-9] indicates that the PTP based on age, sex, and nature of symptoms in current patients is approximately one third of that predicted by the model used in the 2013 version of the ESC guidelines [10, 11]. The updated PTPs, including PTPs in patients presenting with dyspnea, are displayed in - Fig. 2. It should, however, be noted that the PTPs are based mainly on patients from countries with low cardiovascular disease risk and PTP may vary between different regions and countries.

The reduced PTP has important consequences on the evaluation of patients with suspected obstructive CAD. An overestimation of PTP is probably an important contributory factor to a low diagnostic yield of noninvasive and invasive testing. The noninvasive diagnostic tests of obstructive CAD have the best performance in patients with an intermediate likelihood of disease (>15\%). However, if diagnostic testing was deferred in patients with new PTP $<15 \%$, this would result in a large increase in the proportion of patients in whom diagnostic testing is not recommended. In data derived from the PROMISE (Prospective Multicenter Imaging Study for Evaluation of Chest Pain) trial, 50\% of patients previously classified as having an intermediate PTP of obstructive CAD were reclassified to a PTP $<15 \%$ according to the new PTP [8]. In data derived from the pooled analysis [6], $57 \%$ of all patients had a PTP $<15 \%$.

Studies have shown that an outcome in patients with the new PTP of up to $15 \%$ is good (annual risk of cardiovascular death or myocardial infarction [MI] $<1 \%$; $[8,9]$ ). Hence, it would be safe to defer routine testing in patients with PTP $<15 \%$, thus reducing unnecessary procedures. However, currently there are no randomized controlled trials that include evaluation of outcomes with a "no-test" strategy. Therefore, performing diagnostic testing also in patients with a new PTP of $5-15 \%$ more closely reflects current clinical practice and may be considered appropriate, particularly if symptoms are limiting and require clarification [1, 12]. Patient preference, local resources and availability of tests, clinical judgment, and appropriate patient information remain important for the decision to proceed with noninvasive diagnostic testing in an individual patient when the PTP is $5-15 \%$, and the higher likelihood of a false-positive test must be considered [1]. Patients with a very low PTP $(\leq 5 \%)$ can be assumed to have such a low probability of disease that diagnostic testing should be performed only for compelling reasons [1].

A concept of clinical likelihood of obstructive CAD has been introduced to consider modifiers of PTP beyond age, sex, and nature of symptoms. Clinical models that incorporate information on risk factors for cardiovascular disease, resting electrocardiogram (ECG) changes (Q-wave and changes in ST-segment or T-wave), LV dysfunction suggestive of CAD, findings of exercise ECG or coronary calcification provide improved identification of patients with obstructive CAD compared with age, sex, and symptoms alone [13-16]. The absence of coronary calcium (Agatston score $=0$ ) is associated with a low prevalence of obstructive $\mathrm{CAD}(<5 \%)$ and a low risk of death or non-fatal MI $(<1 \%$ annual risk; $[17,18])$. However, coronary calcium detection by computed tomography is not recommended for identifying individuals with obstructive CAD [1]. Although the optimal use of these factors in improving the PTP assessment has not yet been established, they have implications particularly in refining the likelihood of CAD patients with PTP of $5-15 \%$ based on age, sex, and nature of symptoms.

\section{Diagnostic tests}

Over the past few years, numerous studies have evaluated the performance of diagnostic tests and clinical trials have compared the effects of diagnostic strategies on management and clinical outcomes in patients with suspected CCS. A summary of the performance of diagnostic tests for the detection of anatomically significant ( $>50 \%$ stenosis) or functionally significant (fractional flow reserve, FFR $\leq 0.80$ ) CAD based on recent meta-analyses is shown in $\bullet$ Table 1 [19]. Of note, the performance of a given test in different studies varies for numerous reasons, including selection and referral bias. Therefore, differences between individual diagnostic tests as well as summary estimates 
based on these meta-analyses should be interpreted cautiously.

\section{Anatomical imaging}

Coronary CTA is an anatomical imaging modality that allows for visualization of the coronary artery lumen and wall using an intravenous contrast agent. Coronary CTA provides very high sensitivity for the detection of coronary artery stenoses defined as obstructive by invasive coronary angiography (ICA; - Table 1; [19, 20]) as well as nonobstructive calcified or noncalcified plaques. The specificity of coronary CTA is lower than its sensitivity, particularly in studies using invasive FFR rather than ICA as the reference standard (• Fig. 1). Stenoses estimated to be $50-90 \%$ by visual inspection are not necessarily functionally significant, i.e., they do not always induce myocardial ischemia. Therefore, either noninvasive or invasive functional testing is recommended for further evaluation of angiographic stenosis detected by coronary CTA or invasive angiography, unless a very high grade $(>90 \%$ diameter stenosis) stenosis is detected via invasive angiography [1].

Poor image quality and severe calcifications may lead to overestimation of stenosis severity by coronary CTA, particularly by non-experienced readers [21]. Therefore, coronary CTA is not recommended when extensive coronary calcification, irregular heart rate, significant obesity, inability to cooperate with breath hold commands, or any other condition makes good image quality unlikely [1]. In patients with previous revascularization (bypass grafts, stents), the accuracy of coronary CTA is frequently impaired by blooming artifacts and incomplete evaluation of native vessels [22]. Acquisition protocols for coronary CTA should include special measures to keep radiation exposure as low as possible [23].

Prospective registries have shown that the absence of stenosis in coronary CTA is associated with good prognosis [24, 25]. The PROMISE trial randomized 10,003 symptomatic patients referred to noninvasive testing for suspected CAD to either coronary CTA or functional testing as the first diagnostic test [26]. The

Herz 2020 - 45:409-420 https://doi.org/10.1007/s00059-020-04935-x

(c) The Author(s) 2020

A. Saraste $\cdot$ J. Knuuti

\section{ESC 2019 guidelines for the diagnosis and management of chronic coronary syndromes. Recommendations for cardiovascular imaging}

Abstract

The European Society of Cardiology (ESC) has recently published new guidelines on the diagnosis and management of chronic coronary syndromes (CCS). Due to variable symptoms, objective tests are often necessary to confirm the diagnosis, exclude alternative diagnoses, and assess the severity of underlying disease. This review provides a summary of the main diagnostic strategies listed in the guidelines for evaluation of patients suspected of having obstructive coronary artery disease (CAD). Based on data from contemporary cohorts of patients referred for diagnostic testing, the pre-test probabilities of obstructive CAD based on age, sex, and symptoms have been adjusted substantially downward compared with the previous guidelines. Further, a new concept of "clinical likelihood of CAD" was introduced accounting for the impact of various risk factors and modifiers on the pre-test probability. Noninvasive functional imaging for myocardial ischemia, coronary computed tomography angiography, or invasive coronary angiography combined with functional evaluation is recommended as the initial strategy to diagnose CAD in symptomatic patients, unless obstructive CAD can be excluded by clinical assessment alone. When available, imaging tests are recommended as noninvasive modalities instead of exercise electrocardiograms.

\section{Keywords}

Coronary computed tomography angiography · Echocardiography · Single-photon emission computed tomography - Cardiac magnetic resonance P Positron emission computed tomography

\section{ESC-Leitlinien 2019 für die Diagnose und Therapie von chronischen Koronarsyndromen. Empfehlungen für die kardiovaskuläre Bildgebung}

\section{Zusammenfassung}

Die European Society of Cardiology (ESC) hat kürzlich neue Leitlinien zur Diagnose und Therapie chronischer Koronarsyndrome (CCS) publiziert. Aufgrund der Variabilität der Symptome sind häufig objektive Untersuchungen notwendig, um die Diagnose zu bestätigen, alternative Diagnosen auszuschließen und die Schwere der zugrunde liegenden Erkrankung zu bestimmen. Die vorliegende Übersichtsarbeit bietet eine Zusammenfassung der wesentlichen diagnostischen Strategien, die in den Leitlinien zur Beurteilung von Patienten mit Verdacht auf das Vorliegen einer stenosierenden koronaren Herzkrankheit (KHK) aufgeführt sind. Auf der Grundlage von Daten aktueller Patientenkohorten, die zur diagnostischen Abklärung überwiesen worden waren, wurden die Vortestwahrscheinlichkeiten einer stenosierenden KHK auf der Basis von Alter, Geschlecht und Symptomen im Vergleich zu früheren Leitlinien deutlich nach unten korrigiert. Darüber hinaus wurde ein neues Konzept der „klinischen Wahrscheinlichkeit einer KHK" eingeführt, welches den Einfluss verschiedener Risikofaktoren und Modifikatoren der Vortestwahrscheinlichkeit berücksichtigt. Als initiale Strategie zur Diagnose einer KHK bei Patienten mit Symptomen wird die nichtinvasive funktionelle bildgebende Untersuchung auf Myokardischämie, die Computertomographie-Angiographie der Koronarien oder die invasive Koronarangiographie in Kombination mit einer Funktionsuntersuchung empfohlen, wenn die stenosierende KHK nicht durch alleinige klinische Untersuchung ausgeschlossen werden kann. Wenn verfügbar, werden bildgebende Untersuchungen als nichtinvasive Modalitäten anstelle des Belastungs-EKG empfohlen.

\section{Schlüsselwörter}

Koronare ComputertomographieAngiographie - Echokardiographie · Einzelphotonenemissionscomputertomographie $\cdot$ Kardiale Magnetresonanztomographie Positronenemissionscomputertomographie 


\begin{tabular}{|c|c|c|}
\hline Recommendations & Class $^{a}$ & Level ${ }^{b}$ \\
\hline $\begin{array}{l}\text { A resting transthoracic echocardiogram is recommended in all patients for: } \\
\text { a) Exclusion of alternative causes of angina; } \\
\text { b) Identification of regional wall-motion abnormalities suggestive of CAD; } \\
\text { c) Measurement of LVEF for risk-stratification purpose; } \\
\text { d) Evaluation of diastolic function. }\end{array}$ & 1 & B \\
\hline $\begin{array}{l}\text { Ultrasound of the carotid arteries should be considered, and be performed by } \\
\text { adequately trained clinicians, to detect plaque in patients with suspected CCS } \\
\text { without known atherosclerotic disease. }\end{array}$ & Ila & C \\
\hline CMR may be considered in patients with an inconclusive echocardiographic test. & Ilb & C \\
\hline Chest $X$-ray in initial diagnostic management of patients with suspected CAD & & \\
\hline $\begin{array}{l}\text { Chest X-ray is recommended for patients with an atypical presentation, signs and } \\
\text { symptoms of } \mathrm{HF} \text {, or suspicion of pulmonary disease. }\end{array}$ & 1 & C \\
\hline $\begin{array}{l}\text { Use of diagnostic imaging tests in initial diagnostic management of symptomatic p } \\
\text { suspected CAD }\end{array}$ & & \\
\hline $\begin{array}{l}\text { Non-invasive functional imaging for myocardial ischaemia or coronary CTA is } \\
\text { recommended as the initial test for diagnosing CAD in symptomatic patients in whom } \\
\text { obstructive CAD cannot be excluded by clinical assessment alone. }\end{array}$ & & B \\
\hline $\begin{array}{l}\text { It is recommended that selection of the initial non-invasive diagnostic test is done } \\
\text { based on clinical likelihood of CAD and other patient characteristics that influence test } \\
\text { performance, local expertise, and the availability of tests. }\end{array}$ & I & c \\
\hline $\begin{array}{l}\text { Functional imaging for myocardial ischaemia is recommended if coronary CTA has } \\
\text { shown CAD of uncertain functional significance or is not diagnostic. }\end{array}$ & 1 & B \\
\hline $\begin{array}{l}\text { Invasive angiography is recommended as an alternative test to diagnose CAD in } \\
\text { patients with a high clinical likelihood, severe symptoms refractory to medical therapy } \\
\text { or typical angina at a low level of exercise, and clinical evaluation that indicates high } \\
\text { event risk. Invasive functional assessment must be available and used to } \\
\text { evaluate stenoses before revascularization, unless very high grade (>90\% diameter } \\
\text { stenosis). }\end{array}$ & I & B \\
\hline $\begin{array}{l}\text { Invasive coronary angiography with the availability of invasive functional evaluation } \\
\text { should be considered for confirmation of the diagnosis of CAD in patients with an } \\
\text { uncertain diagnosis on non-invasive testing. }\end{array}$ & IIa & B \\
\hline $\begin{array}{l}\text { Coronary CTA should be considered as an alternative to invasive angiography if } \\
\text { another non-invasive test is equivocal or non-diagnostic. }\end{array}$ & IIla & c \\
\hline $\begin{array}{l}\text { Coronary CTA is not recommended when extensive coronary calcification, irregular } \\
\text { heart rate, significant obesity, inability to cooperate with breath-hold commands, or } \\
\text { any other conditions make obtaining good image quality unlikely. }\end{array}$ & IIII & c \\
\hline $\begin{array}{l}\text { Coronary calcium detection by } \mathrm{CT} \text { is not recommended to identify individuals with } \\
\text { obstructive CAD. }\end{array}$ & IIII & c \\
\hline \multicolumn{3}{|c|}{$\begin{array}{l}\text { Performing exercise electrocardiogram in the initial diagnostic management of patients with suspected } \\
\text { CAD }\end{array}$} \\
\hline $\begin{array}{l}\text { Exercise ECG is recommended for assessment of exercise tolerance, symptoms, } \\
\text { arrhythmias, blood pressure response, and event risk in selected patients. }\end{array}$ & 1 & c \\
\hline $\begin{array}{l}\text { Exercise ECG may be considered as an alternative test to rule in or rule out CAD when } \\
\text { non-invasive imaging is not available. }\end{array}$ & IIb & B \\
\hline $\begin{array}{l}\text { Exercise ECG may be considered in patients on treatment to evaluate control of } \\
\text { symptoms and ischaemia. }\end{array}$ & IIb & c \\
\hline $\begin{array}{l}\text { Exercise ECG is not recommended for diagnostic purposes in patients with } \geq 0.1 \mathrm{mV} \text { ST- } \\
\text { segment depression on resting ECG or who are being treated with digitalis. }\end{array}$ & & c \\
\hline
\end{tabular}

Fig. $1 \Delta$ Summary of recommendations for imaging in the 2019 ESC guidelines on the management of chronic coronary syndromes [1]

trial demonstrated no difference in the primary outcome of all-cause mortality, myocardial infarction, hospitalization for unstable angina, or major complications of cardiovascular procedures or diagnostic testing between coronary CTA and functional testing after 25 months of follow-up (3.3\% vs. $3.0 \%$; [26]). The randomized SCOT-HEART (Scottish Computed Tomography of the Heart) trial included 8000 patients with suspected obstructive $\mathrm{CAD}$ and demonstrated sig- nificantly lower rate of the combined endpoint of cardiovascular death or nonfatal MI $(2.3 \%$ vs. $3.9 \%$ during 5-year follow-up) in patients for whom coronary CTA was performed in addition to routine testing, which consisted predominantly of exercise ECG $[27,28]$. Rates of ICA and revascularizations were not different among the groups, but preventive therapies were more often initiated in the CTA group than in the control group [28].

Coronary CTA can be complemented by stress computed tomography (CT) myocardial perfusion imaging or off-line "virtual" CT-based FFR (FFRCT) using datasets acquired by $\mathrm{CT}$ at rest to improve detection of functionally significant CAD defined by invasive FFR [29]. Results of retrospective registries, trial substudies, and small randomized trials have demonstrated that non-ischemic FFRCT results are associated with a favorable prognosis [30-32]. In the absence of comparative prospective outcome trials, these emerging modalities were discussed in the guidelines, but no specific recommendations on their use were given.

\section{Functional imaging tests}

Functional imaging for ischemia includes myocardial perfusion imaging with single-photon emission computed tomography (SPECT) or positron emission computed tomography (PET), stress echocardiography, or stress CMR. Detection of obstructive CAD is based on perfusion abnormalities or ischemic wall motion abnormalities provoked by exercise or pharmacological stress (• Fig. 3).

Compared with coronary CTA, functional imaging tests have higher specificity for the detection of hemodynamically significant coronary stenosis in studies that have used invasive FFR as the reference standard (- Table 1; [19]). Ischemia on noninvasive testing has also been shown to predict symptom relief upon revascularization [33]. In comparative trials and a network metaanalysis, the use of functional imaging tests resulted in fewer referrals for ICA compared with a strategy relying on anatomical imaging or exercise ECG [34-37]. It should, however, be noted that 


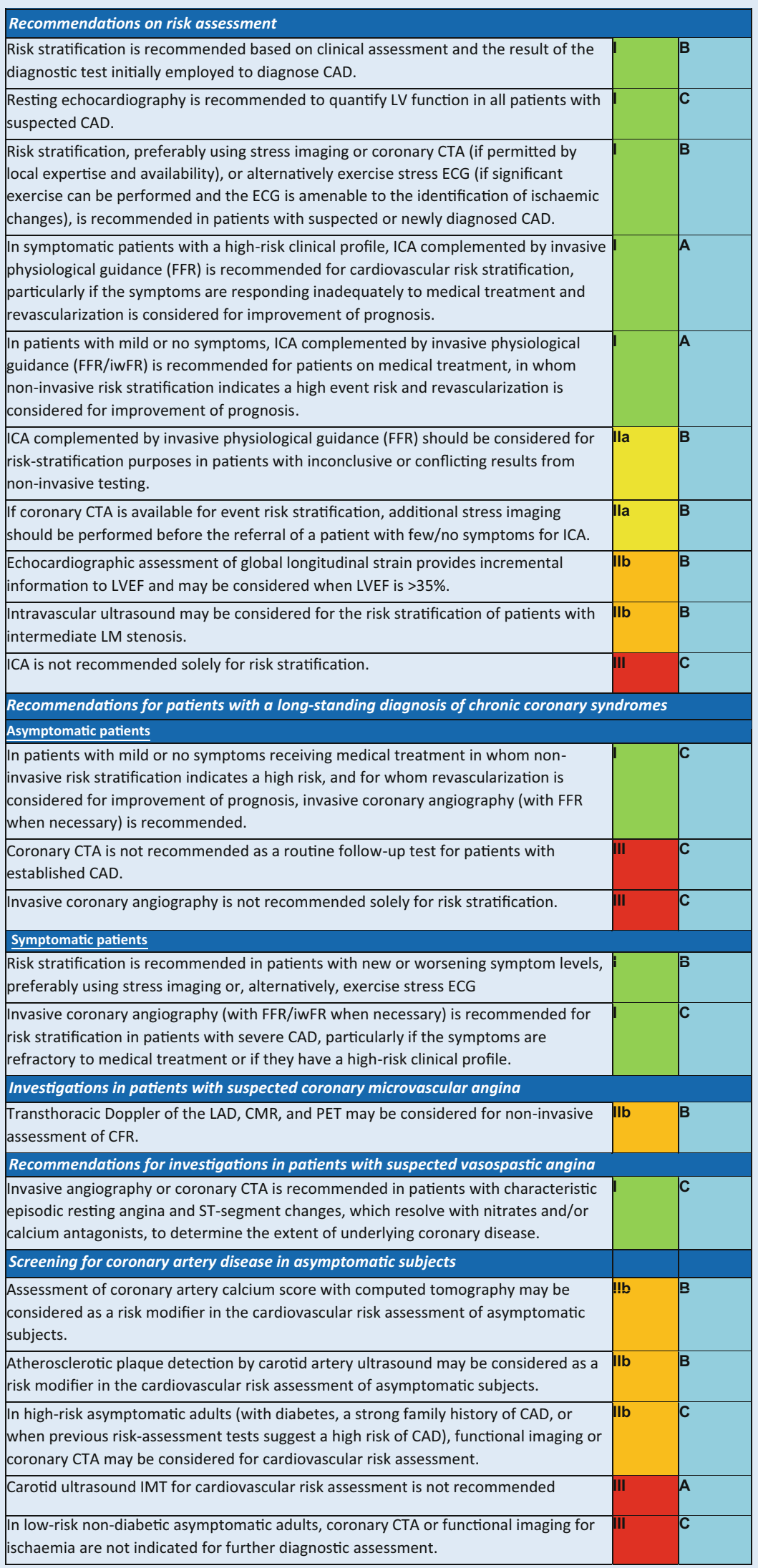

Fig. $1 \Delta$ (continued) [1] the presence of coronary atherosclerosis that does not cause luminal narrowing to the extent that provokes myocardial ischemia remains undetected by functional testing [38]. Therefore, in the presence of a negative functional test result, patients should receive risk-factor modification based on commonly applied risk charts and recommendations [39].

Functional imaging tests are effective diagnostic tools for risk stratification of patients with CCS. A normal functional test result is associated with a low $(\leq 1 \%$ per year) subsequent rate of cardiac death and MI [40]. By contrast, stress-induced wall motion abnormalities or reversible perfusion defects corresponding to $\geq 10 \%$ of the total LV myocardium have been reported across a number of prognostic series to denote moderate-severe ischemia associated with a high event rate in CCS (annual rate of cardiovascular death or MI $>3 \%$; [41]). Based on observational studies, these patients may benefit from ICA and revascularization [42]. However, after publication of the guidelines, the prospective randomized ISCHEMIA (International Study of Comparative Health Effectiveness with Medical and Invasive Approaches) trial did not find evidence that an initial invasive strategy, as compared with an initial conservative strategy, reduced the risk of ischemic cardiovascular events or death from any cause over a median of 3.2 years in such patients [43].

\section{Role of exercise electro- cardiogram}

Compared with exercise ECG, noninvasive functional imaging tests not only have the advantage of indicating the location of ischemia, but also of superior diagnostic performance for the detection of obstructive CAD (• Table 1; [19]). Exercise ECG has limited power to rule in or rule out obstructive CAD (• Table 1; [19]). As discussed earlier, randomized clinical trials have shown that the addition of coronary CTA or functional imaging clarifies the diagnosis, enables targeting of preventive therapies and interventions, and potentially reduces the risk of MI compared with a diagnostic 
Hier steht eine Anzeige.

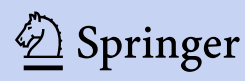


Hier steht eine Anzeige.

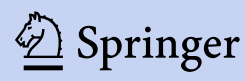




\begin{tabular}{|c|c|c|c|c|c|c|c|c|}
\hline & \multicolumn{6}{|c|}{ Chest pain } & \multicolumn{2}{c|}{ Dyspnea } \\
\hline & \multicolumn{2}{|c|}{ Typical } & \multicolumn{2}{c|}{ Atypical } & \multicolumn{2}{c|}{ Non-anginal } & & \\
\hline Age & Men & Women & Men & Women & Men & Women & Men & Women \\
\hline $\mathbf{3 0 - 3 9}$ & $3 \%$ & $5 \%$ & $4 \%$ & $3 \%$ & $1 \%$ & $1 \%$ & $0 \%$ & $3 \%$ \\
\hline $\mathbf{4 0 - 4 9}$ & $22 \%$ & $10 \%$ & $10 \%$ & $6 \%$ & $3 \%$ & $2 \%$ & $12 \%$ & $3 \%$ \\
\hline $\mathbf{5 0 - 5 9}$ & $32 \%$ & $13 \%$ & $17 \%$ & $6 \%$ & $11 \%$ & $3 \%$ & $20 \%$ & $9 \%$ \\
\hline $\mathbf{6 0 - 6 9}$ & $44 \%$ & $16 \%$ & $26 \%$ & $11 \%$ & $22 \%$ & $6 \%$ & $27 \%$ & $14 \%$ \\
\hline $\mathbf{7 0 +}$ & $52 \%$ & $27 \%$ & $34 \%$ & $19 \%$ & $24 \%$ & $10 \%$ & $32 \%$ & $12 \%$ \\
\hline
\end{tabular}

Fig. $2 \Delta$ Pre-test probabilities of obstructive coronary artery disease $(C A D)$ in 15,815 symptomatic patients according to age, sex, and the nature of symptoms in pooled analysis of contemporary data. In addition to the classic Diamond and Forrester classes, patients with dyspnea only or dyspnea as the primary symptom are included. The dark blue shaded regions denote the groups in which noninvasive testing is most beneficial (pre-test probability [PTP] $>15 \%$ ). The light blue shaded regions denote the groups with PTP of CAD between 5 and $15 \%$ in whom diagnostic testing may be considered after assessing the overall clinical likelihood based on modifiers of PTP. (Reprinted by permission of Oxford University Press on behalf of the European Society of Cardiology from reference [6])

\section{PTP based on sex, age and nature of symptoms}

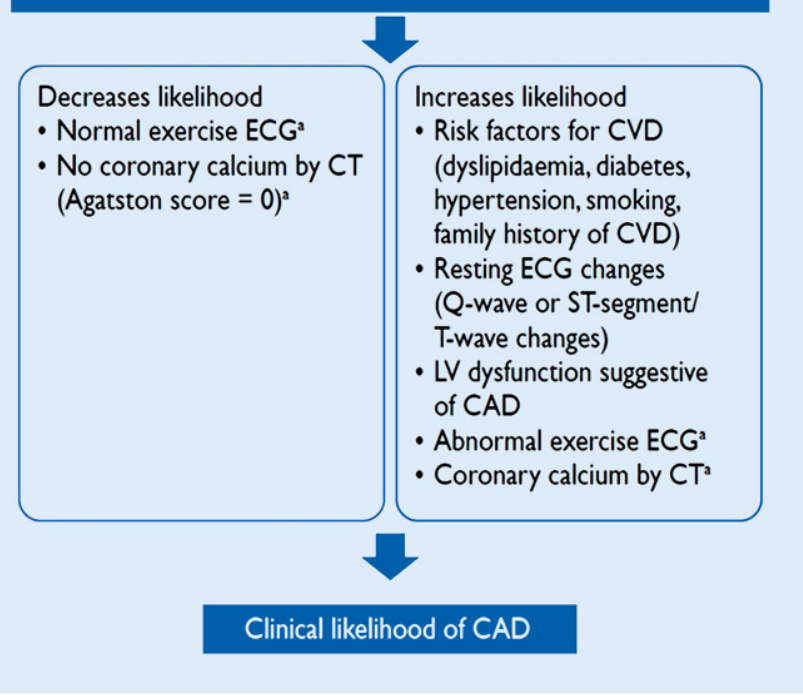

Fig. $3<$ Determinants of clinical likelihood of obstructive CAD. $C A D$ coronary artery disease, $C T$ computed tomography, CVD cardiovascular disease, ECG electrocardiogram, $L V$ left ventricular, PTP pre-test probability. ${ }^{a}$ When available. (Reprinted by permission of Oxford University Press on behalf of the European Society of Cardiology, www.escardio.org/ Guidelines, from [1]) workup relying on exercise ECG. Therefore, the 2019 ESC guidelines recommend the use of an imaging diagnostic test instead of exercise ECG as the initial noninvasive test for diagnosing obstructive CAD always if possible [1]. However, an exercise ECG provides complementary clinically useful information beyond ECG changes and valuable prognostic information. Therefore, exercise ECG has a role in the assessment of symptoms, STsegment changes, exercise tolerance, arrhythmias, blood pressure response, and event risk [1], and thereby helps to inform about the clinical likelihood of CAD as well as an appropriate diagnostic and therapeutic strategy.
Either functional imaging for myocardial ischemia or coronary CTA is recommended as the initial noninvasive tests for diagnosing CAD in symptomatic patients in whom obstructive CAD cannot be excluded by clinical assessment alone [1]. It is recommended that the choice of the initial noninvasive diagnostic test is based on the clinical likelihood of CAD and other patient characteristics that influence test performance as well as on local expertise and availability of tests.

The likelihood ratios of diagnostic tests constitute useful parameters of their ability to correctly classify patients, and can be used to facilitate the selection of the most useful test in any given patient [19]. Each noninvasive diagnostic test has a particular range of clinical likelihood of obstructive CAD where the usefulness of its application is maximal. Given a clinical likelihood of obstructive CAD and the likelihood ratios of a particular test, one can assess the post-test probability of obstructive CAD after performing such a test. Using this approach, one can estimate the optimal ranges of clinical likelihood for each test where they can reclassify patients from intermediate to either low or high post-test probability of CAD (• Fig. 5; [19]).

Coronary CTA is the preferred test in patients within the lower range of clinical likelihood of CAD, no previous diagnosis of CAD, and characteristics associated with a high likelihood of good image quality. It can accurately rule out both 


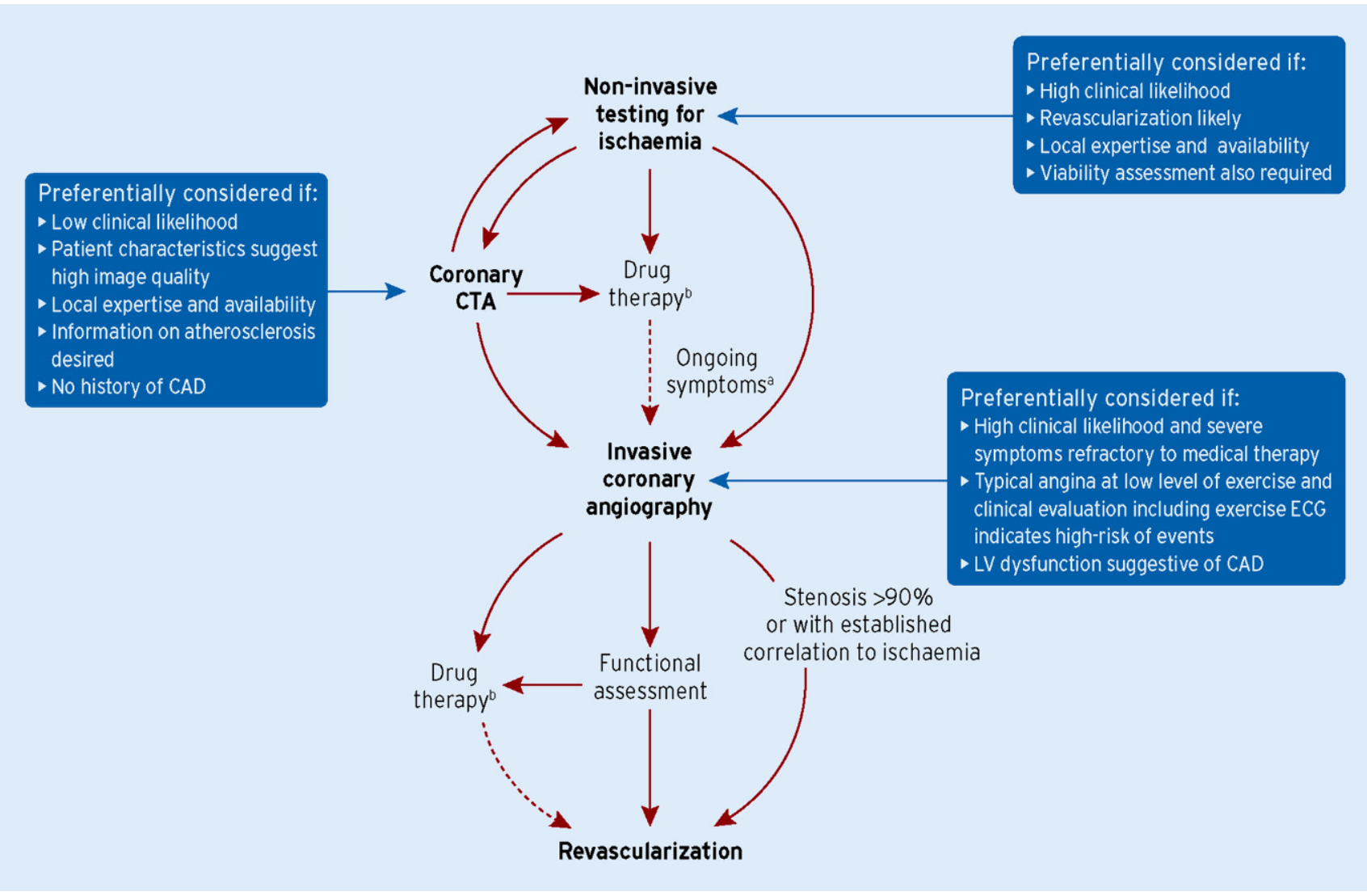

Fig. $4 \Delta$ Main diagnostic pathways in symptomatic patients with suspected obstructive coronary artery disease. CAD coro-

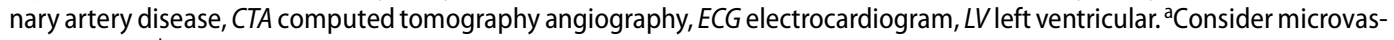
cular angina. ${ }^{\mathrm{b}}$ Antianginal medications and risk factor modification. (Reprinted by permission of Oxford University Press on behalf of the European Society of Cardiology, www.escardio.org/Guidelines, from [1])

anatomically and functionally significant $\mathrm{CAD}$, and detect subclinical coronary atherosclerosis (• Fig. 5). Coronary CTA should also be considered as an alternative to ICA if another noninvasive test is equivocal or nondiagnostic.

The noninvasive functional tests for ischemia typically have better rule-in power. For revascularization decisions, functional evaluation of ischemia (either noninvasive or invasive) is required in most patients. Therefore, functional noninvasive testing may be preferred in patients at the higher range of clinical likelihood, if revascularization is likely or the patient has previously been diagnosed with CAD. Functional imaging for myocardial ischemia is also recommended if coronary CTA has shown CAD of uncertain functional significance or is not diagnostic.

Direct ICA is recommended as an alternative to noninvasive testing in order to diagnose $\mathrm{CAD}$ in patients with a high clinical likelihood and severe symptoms refractory to medical therapy or typical angina at a low level of exercise and clinical evaluation that indicates high event risk [1]. Invasive functional assessment must be available and used to evaluate stenoses before revascularization, unless they are of very high grade ( $>90 \%$ diameter stenosis).

Risks related to different diagnostic tests need to be weighed against the benefits to the individual [44]. For example, exposure to ionizing radiation associated with coronary CTA and nuclear perfusion imaging needs to be taken into account, especially in young individuals. Similarly, contraindications to pharmacological stressors and contrast agents (iodine-based contrast agents and gadolinium-based chelates) need to be considered. When testing is used appropriately, the clinical benefit from accurate diagnosis and therapy exceeds the projected risks of testing itself [44].

\section{Angina without obstructive disease in the epicardial coronary arteries}

The possibility of a microcirculatory origin of angina should be considered in patients with clear-cut angina and coronary vessels that are either normal or have mild stenosis deemed functionally nonsignificant on ICA or CTA. Impaired microcirculatory conductance can be diagnosed by measuring coronary flow reserve noninvasively with transthoracic Doppler echocardiography (by imaging left anterior descending flow; [45]), CMR (myocardial perfusion index; [46]), or PET [47]. However, noninvasive methods provide limited assessment of microvascularfunction, because assessment of endothelial function (arteriolar dysregulation) in the coronary microcirculation requires selective acetylcholine infusion into the epicardial vessels. In patients with suspected vasospastic angina 


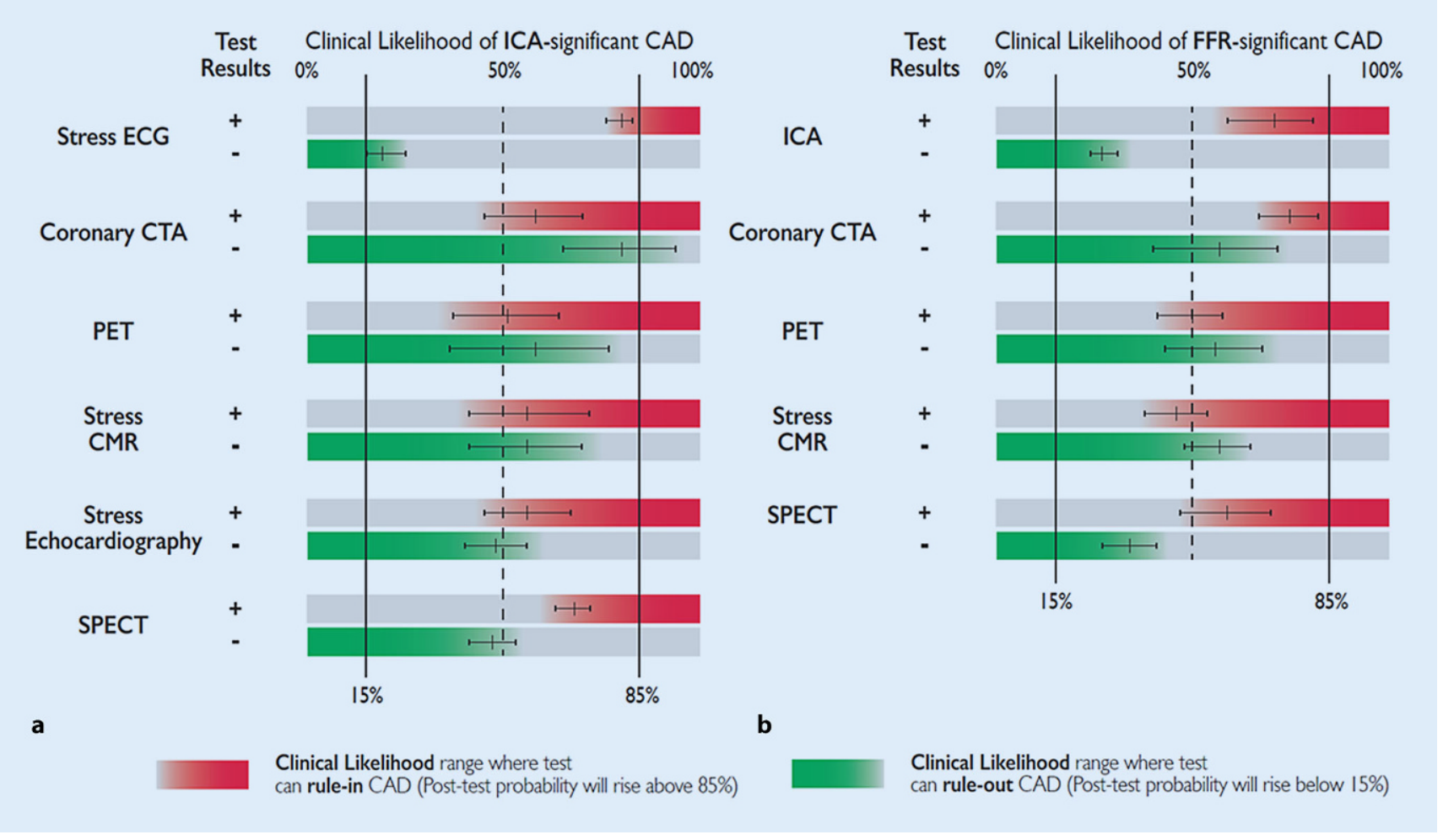

Fig. $5 \Delta$ Ranges of clinical likelihood of CAD in which a given test can rule in (red) or rule out ( $g r e e n$ ) obstructive CAD. The graph displays in red the range of clinical likelihood of CAD when a given test can rule in CAD when positive. The green part shows the range of clinical likelihood of CAD when a given test can rule out CAD when negative. The ideal range of clinical likelihood for a given test is when the red and green colors overlap and the test can simultaneously rule in and rule out CAD depending the test result. a Reference standard is anatomical assessment using ICA. $\mathbf{b}$ Reference standard is functional assessment using FFR. Note, in $\mathbf{b}$, the data with stress echocardiography and SPECT are more limited than with the other techniques. The crosshairs mark the mean value and their $95 \%$ confidence intervals. CAD coronary artery disease, CMR cardiac magnetic resonance, CTA computed tomography angiography, ECG electrocardiogram, FFR fractional flow reserve, ICA invasive coronary angiography, $P E T$ positron emission tomography, SPECT single-photon emission computed tomography. (Reprinted by permission of Oxford University Press on behalf of the European Society of Cardiology, www.escardio.org/Guidelines, from [1])

and documented ECG changes, coronary CTA or ICA is indicated to rule out the presence of fixed coronary stenosis.

\section{Conclusion}

The pre-test probability (PTP) estimations of coronary artery disease (CAD) based on age, sex, and nature of symptoms have undergone a major update with significantly lower probabilities than in previous estimates. In addition, a new phrase-“clinical likelihood of CAD"-that incorporates other modifiers of PTP beyond age, gender, and nature of symptoms has been introduced. Noninvasive functional imaging for myocardial ischemia, coronary computed tomography angiography, or invasive coronary angiography combined with functional evaluation may be used as the initial test to rule out or establish the diagnosis of chronic coronary syndromes. Selection of the initial noninvasive diagnostic test is based on the clinical likelihood of CAD, the test performance in ruling in or ruling out obstructive CAD, patient characteristics, local expertise, and the availability of the test. For revascularization decisions, both anatomy and functional evaluation are to be considered.

\section{Corresponding address}

\section{Juhani Knuuti}

Turku PET Centre, Turku University Hospital and University of Turku

Kiinamllynkatu 4-8, 20520 Turku, Finland juhani.knuuti@tyks.fi
Funding. Open access funding provided by University of Turku (UTU) including Turku University Central Hospital.

\section{Compliance with ethical guidelines}

Conflict of interest. A. Saraste discloses speaker fees from Abbott, Astra Zeneca, and Bayer, and consultancy fees from Amgen and Astra Zeneca. J. Knuuti discloses speaker fees from GE Healthcare, Merck, Lundbeck, and Bayer, and study protocol constancy fees from GE Healthcare and AstraZeneca outside of submitted work.

For this article no studies with human participants or animals were performed by any of the authors. All studies performed were in accordance with the ethical standards indicated in each case.

Open Access. This article is licensed under a Creative Commons Attribution 4.0 International License, which permits use, sharing, adaptation, distribution and re- 
production in any medium or format, as long as you give appropriate credit to the original author(s) and the source, provide a link to the Creative Commons licence, and indicate if changes were made. The images or other third party material in this article are included in the article's Creative Commons licence, unless indicated otherwise in a credit line to the material. If material is not included in the article's Creative Commons licence and your intended use is not permitted by statutory regulation or exceeds the permitted use, you will need to obtain permission directly from the copyright holder. To view a copy of this licence, visit http://creativecommons.org/licenses/by/4.0/.

\section{References}

1. Knuuti J, Wijns W, Saraste A et al (2020) 2019 ESC guidelines on the diagnosis and management of chronic coronary syndromes: the task force for diagnosis and management of chronic coronary syndromes of the European society of cardiology (ESC). Eur Heart J 41:407-477. https://doi.org/10. 1093/eurheartj/ehz425

2. Zimmermann FM, Omerovic E, Fournier $S$ et al (2019) Fractional flow reserve-guided percutaneous coronary intervention vs. medical therapy for patients with stable coronary lesions: metaanalysis of individual patient data. Eur Heart J 40:180-186. https://doi.org/10.1093/eurheartj/ ehy812

3. Stanton T, Leano R, Marwick TH (2009) Prediction of all-cause mortality from global longitudinal speckle strain: comparison with ejection fraction and wall motion scoring. Circ Cardiovasc Imaging 2:356-364. https://doi.org/10.1161/ CIRCIMAGING.109.862334

4. Haugaa KH, Grenne BL, Eek CH et al (2013) Strain echocardiography improves risk prediction of ventricular arrhythmias after myocardial infarction. JACC Cardiovasc Imaging 6:841-850. https://doi.org/10.1016/j.jcmg.2013.03.005

5. Ersboll M, Valeur N, Mogensen UM et al (2013) Prediction of all-cause mortality and heart failure admissions from global left ventricular longitudinal strain in patients with acute myocardial infarction and preserved left ventricular ejection fraction. J Am Coll Cardiol 61:2365-2373. https:// doi.org/10.1093/eurheartj/ehy812

6. Juarez-Orozco LE, Saraste A, Capodanno D et al (2019) Impact of a decreasing pre-test probability on the performance of diagnostictestsfor coronary artery disease. Eur Heart J Cardiovasc Imaging 20:1198-1207. https://doi.org/10.1093/ehjci/ jez054

7. Cheng VY, Berman DS, Rozanski A et al (2011) Performance of the traditional age, sex, and angina typicality-based approach for estimating pretest probability of angiographically significant coronary artery disease in patients undergoing coronary computed tomographic angiography: results from the multinational coronary $\mathrm{CT}$ angiography evaluation for clinical outcomes: an international multicenter registry (CONFIRM). Circulation 124:2423-2432. https://doi.org/10. 1161/CIRCULATIONAHA.111.039255

8. Foldyna B, Udelson JE, Karady J et al (2019) Pretest probability for patients with suspected obstructive coronary artery disease: re-evaluating DiamondForrester for the contemporary era and clinical implications: insights from the PROMISE trial. Eur Heart J Cardiovasc Imaging 20:574-581. https:// doi.org/10.1093/ehjci/jey182
9. Reeh J, Therming CB, Heitmann M et al (2018) Prediction of obstructive coronary artery disease and prognosis in patients with suspected stable angina. Eur Heart J 40:1426-1435. https://doi.org/ 10.1093/eurheartj/ehy806

10. Genders TS, Steyerberg EW, Alkadhi H et al (2011) A clinical prediction rule for the diagnosis of coronary artery disease: validation, updating, and extension. Eur Heart J 32:1316-1330. https://doi. org/10.1093/eurheartj/ehr014

11. Montalescot G, Sechtem U, Achenbach S et al (2013) 2013 ESC guidelines on the management of stable coronary artery disease: the task force on the management of stable coronary artery disease of the European Society of Cardiology. Eur Heart J 34:2949-3003. https://doi.org/10.1093/ eurheartj/eht296

12. Adamson PD, Newby DE, Hill CL et al (2018) Comparison of international guidelines for assessment of suspected stable angina: insights from the PROMISE and SCOT-HEART. JACC Cardiovasc Imaging 11:1301-1310. https://doi. org/10.1016/j.jcmg.2018.06.021

13. Genders TS, Steyerberg EW, Hunink MG et al (2012) Prediction model to estimate presence of coronary artery disease: retrospective pooled analysis of existing cohorts. BMJ 344:e3485. https://doi.org/ 10.1136/bmj.e3485

14. Winther S, Nissen L, Westra J et al (2019) Pretest probability prediction in patients with a low to intermediate probability of coronary artery disease: a prospective study with a fractional flow reserve endpoint. Eur Heart J Cardiovasc Imaging 20:1208-1218. https://doi.org/10.1093/ ehjci/jez058

15. Wasfy MM, Brady TJ, Abbara S et al (2012) Comparison of the Diamond-Forrester method and Duke Clinical Score to predict obstructive coronary artery disease by computed tomographic angiography. Am J Cardiol 109:998-1004. https:// doi.org/10.1016/j.amjcard.2011.11.028

16. Fox K, Garcia MA, Ardissino D et al (2006) Guidelines on the management of stable angina pectoris: executive summary: the task force on the management of stable angina pectoris of the European Society of Cardiology. Eur Heart J 27:1341-1381

17. Budoff MJ, Mayrhofer T, Ferencik M et al (2017) Prognostic value of coronary artery calcium in the PROMISE study (prospective multicenter imaging study for evaluation of chest pain). Circulation 136:1993-2005. https://doi.org/10.1016/j.jcmg 2019.09.012

18. Villines TC, Hulten EA, Shaw LJ et al (2011) Prevalence and severity of coronary artery disease and adverse events among symptomatic patients with coronary artery calcification scores of zero undergoing coronary computed tomography angiography: results from the CONFIRM (Coronary CT Angiography Evaluation for Clinical Outcomes: An International Multicenter) registry. J Am Coll Cardiol 58:2533-2540. https://doi.org/10.1016/j. jacc.2011.10.851

19. Knuuti J, Ballo H, Juarez-Orozco LE et al (2018) The performance of non-invasive tests to rule-in and rule-out significant coronary artery stenosis in patients with stable angina: a meta-analysis focused on post-test disease probability. Eur Heart J 39:3322-3330. https://doi.org/10.1093/ eurheartj/ehy267

20. Menke J, Kowalski J (2016) Diagnostic accuracy and utility of coronary CT angiography with consideration of unevaluable results: a systematic review and multivariate Bayesian random-effects meta-analysis with intention to diagnose. Eur Radiol 26:451-458. https://doi.org/10.1007/ s00330-015-3831-z

21. Lu MT, Meyersohn NM, Mayrhofer T et al (2018) Central core laboratory versus site interpretation of coronary CT angiography: agreement and association with cardiovascular events in the PROMISE trial. Radiology 287:87-95. https://doi. org/10.1148/radiol.2017172181

22. Leipsic J, Abbara S, Achenbach S et al (2014) SCCT guidelines for the interpretation and reporting of coronary CT angiography: a report of the Society of Cardiovascular Computed Tomography Guidelines Committee. J Cardiovasc Comput Tomogr 8:342-358. https://doi.org/10.1016/j.jcct. 2014.07.003

23. Abbara S, Blanke P, Maroules CD et al (2016) SCCT guidelines for the performance and acquisition of coronary computed tomographic angiography: a report of the society of Cardiovascular Computed Tomography Guidelines Committee: endorsed by the North American Society for Cardiovascular Imaging (NASCl). J Cardiovasc Comput Tomogr 10:435-449. https://doi.org/10.1016/j.jcct.2016. 10.002

24. Hadamitzky M, Freissmuth $B$, Meyer $T$ et al (2009) Prognostic value of coronary computed tomographic angiography for prediction of cardiac events in patients with suspected coronary artery disease. JACC Cardiovasc Imaging 2:404-411. https://doi.org/10.1016/j.jcmg.2008.11.015

25. Min JK, Dunning A, Lin FY et al (2011) Age- and sexrelated differences in all-cause mortality risk based on coronary computed tomography angiography findings results from the International Multicenter CONFIRM (CoronaryCTAngiography Evaluation for Clinical Outcomes: An International Multicenter Registry) of 23,854 patients without known coronary artery disease. J Am Coll Cardiol 58:849-860. https://doi.org/10.1016/j.jacc.2011. 02.074

26. Douglas PS, Hoffmann U, Patel MR et al (2015) Outcomes of anatomical versus functional testing for coronary artery disease. N Engl J Med 372:1291-1300. https://doi.org/10.1056/ NEJMoa1415516

27. SCOT-HEART Investigators (2015) CT coronary angiography in patients with suspected angina due to coronary heart disease (SCOT-HEART): an open-label, parallel-group, multicentre trial. Lancet 385:2383-2391. https://doi.org/10.1016/ S0140-6736(15)60291-4

28. SCOT-HEART Investigators (2018) Coronary CT angiography and 5-year risk of myocardial infarction. NEngl J Med 379:924-933. https://doi. org/10.1056/NEJMoa1805971

29. Celeng C, Leiner T, Maurovich-Horvat P (2019) Anatomical and functional computed tomography for diagnosing hemodynamically significant coronary artery disease: a meta-analysis. JACC Cardiovasc Imaging 12:1316-1325. https://doi. org/10.1016/j.jcmg.2018.07.022

30. Nørgaard BL, Terkelsen CJ, Mathiassen $O N$ et al (2018) Coronary CT angiographic and flow reserve-guided management of patients with stable ischemic heart disease. J Am Coll Cardiol 72:2123-2134. https://doi.org/10.1016/j.jacc. 2018.07.043

31. Lu MT, Ferencik M, Roberts RS et al (2017) Noninvasive FFR derived from coronary CT angiography: management and outcomes in the PROMISE trial. JACC Cardiovasc Imaging 10:1350-1358. https://doi.org/10.1016/j.jcmg. 2016.11.024 
32. Douglas PS, De Bruyne B, Pontone G et al (2016) 1-year outcomes of FFRCT-guided care in patients with suspected coronary disease. J Am Coll Cardiol 68:435-445. https://doi.org/10.1016/j.jacc.2016. 05.057

33. Al-Lamee RK, Shun-Shin MJ, Howard JP et al (2019) Dobutamine stress echocardiography ischemia as a predictor of the placebo-controlled efficacy of percutaneous coronary intervention in stable coronary artery disease: the stress echocardiography-stratified analysis of ORBITA. Circulation 140:1971-1980. https://doi.org/10. 1161/CIRCULATIONAHA.119.042918

34. Siontis GC, Mavridis D, Greenwood JP et al (2018) Outcomes of non-invasive diagnostic modalities for the detection of coronary artery disease: network meta-analysis of diagnostic randomised controlled trials. BMJ 360:k504. https://doi.org/10. 1136/bmj.k504

35. Greenwood JP, Ripley DP, Berry C et al (2016) Effect of care guided by cardiovascular magnetic resonance, myocardial perfusion scintigraphy, or NICE guidelines on subsequent unnecessary angiography rates: the CE-MARC 2 randomized clinical trial. JAMA 316:1051-1060. https://doi. org/10.1001/jama.2016.12680

36. Zacharias K, Ahmed A, Shah BN et al (2017) Relative clinical and economic impact of exercise echocardiography vs. exercise electrocardiography, as first line investigation in patients without known coronary artery disease and new stable angina: a randomized prospective study. Eur Heart J Cardiovasc Imaging 18:195-202. https://doi.org/ 10.1093/ehjci/jew049

37. Karthikeyan G, Guzic Salobir B, Jug B et al (2017) Functional compared to anatomical imaging in the initial evaluation of patients with suspected coronary artery disease: an international, multi-center, randomized controlled trial (IAEA-SPECT/CTA study). J Nucl Cardiol 24:507-517. https://doi.org/10.1007/s12350016-0664-3

38. Hoffmann U, Ferencik M, Udelson JE et al (2017) Prognostic value of noninvasive cardiovascular testing in patients with stable chest pain: insights from the PROMISE trial (prospective multicenter imaging study for evaluation of chest pain). Circulation 135:2320-2332. https://doi.org/10. 1161/CIRCULATIONAHA.117.030578

39. Piepoli MF, Hoes AW, Agewall S et al (2016) 2016 European guidelines on cardiovascular disease prevention in clinical practice: The Sixth Joint Task Force of the European Society of Cardiology and Other Societies on Cardiovascular Disease Prevention in Clinical Practice (constituted by representatives of 10 societies and by invited experts). Developed with the special contribution of the European Association for Cardiovascular Prevention \& Rehabilitation (EACPR). Eur Heart J 37:2315-2381. https://doi.org/10.1093/ eurheartj/ehw106

40. Smulders MW, Jaarsma C, Nelemans PJ et al (2017) Comparison of the prognostic value of negative non-invasive cardiac investigations in patients with suspected or known coronary artery disease - a meta-analysis. Eur Heart J Cardiovasc Imaging 18:980-987. https://doi.org/10.1093/ ehjci/jex014

41. Shaw LJ, Berman DS, Picard MH et al (2014) Comparative definitions for moderate-severe ischemia in stress nuclear, echocardiography, and magnetic resonance imaging. JACC CardiovasC Imaging 7:593-604. https://doi.org/10.1016/j. jcmg.2013.10.021
42. Hachamovitch R, Rozanski A, Shaw LJ et al (2011) Impact of ischaemia and scar on the therapeutic benefit derived from myocardial revascularization vs. medical therapy among patients undergoing stress-rest myocardial perfusion scintigraphy. Eur Heart J 32:1012-1024. https://doi.org/10.1093/ eurheartj/ehq500

43. Maron DJ, Hochman JS, Reynolds HR et al (2020) Initial invasive or conservative strategy for stable coronary disease. N Engl J Med 382:1395-1407. https://doi.org/10.1056/NEJMoa1915922

44. Knuuti J, Bengel F, Bax JJ et al (2014) Risks and benefits of cardiac imaging: an analysis of risks related to imaging for coronary artery disease. Eur Heart J 35:633-638. https://doi.org/10.1093/ eurheartj/eht512

45. Sicari R, Rigo F, Cortigiani L et al (2009) Additive prognostic value of coronary flow reserve in patients with chest pain syndrome and normal or near-normal coronary arteries. Am J Cardiol 103:626-631. https://doi.org/10.1016/j.amjcard. 2008.10.033

46. Liu A, Wijesurendra RS, Liu JMetal (2018) Diagnosis of microvascular angina using cardiac magnetic resonance. J Am Coll Cardiol 71:969-979. https:// doi.org/10.1016/j.jacc.2017.12.046

47. Taqueti VR, Hachamovitch R, Murthy VL et al (2015) Global coronary flow reserve is associated with adverse cardiovascular events independently of luminal angiographic severity and modifies the effect of early revascularization. Circulation 131:19-27. https://doi.org/10.1161/ CIRCULATIONAHA.114.011939

\section{Pneumologische} Intensivmedizin

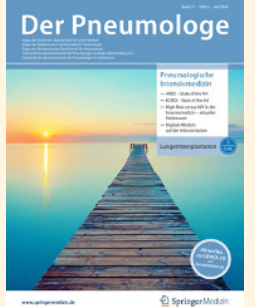

Die Intensivmedizin ist ein wichtiger Schwerpunkt in der Pneumologie. Insbesondere auf der Intensivstation sind moderne Diagnostik und Therapie der Atemwege und der Lunge von größter Bedeutung. Sie finden in Der Pneumologe 04/2020 aktuelle Informationen und praktische Hinweise für das Management des akuten Lungenversagens (ARDS).

Erfahren Sie außerdem, dass der Einsatz von ECMO bereits in früheren Krankheitsstadien des ARDS sinnvoll sein kann, und lesen Sie Wissenswertes zur aktuellen Studienlage und dem Stellenwert der nasal applizierten High Flow Therapie (NHF) zur Verbesserung der Oxygenierung.

- Acute respiratory distress syndrome (ARDS)

- Extrakorporale Membranoxygenierung (ECMO)

- High-flow vs. nicht-invasive Beatmung in der Intensivmedizin

- Digitale Medizin auf der Intensivstation

Suchen Sie noch mehr zum Thema?

Mit e.Med - den maßgeschneiderten Fortbildungsabos von Springer Medizin - haben Sie Zugriff auf alle Inhalte von SpringerMedizin.de. Sie können schnell und komfortabel in den für Sie relevanten Zeitschriften recherchieren und auf alle Inhalte im Volltext zugreifen.

Weitere Infos zu e.Med finden Sie auf springermedizin.de unter „Abos" 